\title{
Investigation into Effects of Scanning Speed on in Vitro Biocompatibility of Selective Laser Melted 316L Stainless Steel Parts
}

\author{
Yitong Shang ${ }^{1}$, Yanping Yuan ${ }^{2}$, Yongzhi Zhang ${ }^{2}$, Dongfang $\mathrm{Li}^{2,3}$ and Yansheng $\mathrm{Li}^{1}$ \\ ${ }^{1}$ College of Mechanical Engineering and Applied Electronics Technology, Beijing University of Technology, Beijing 100124, China \\ ${ }^{2}$ Institute of Laser Engineering, Beijing University of Technology, Beijing 100124, China \\ ${ }^{3}$ Fraunhofer-Institute for Laser Technology, the Federal Republic of Germany
}

\begin{abstract}
In recent years, selective laser melting (SLM) has gained an important place in fabrication due to their strong individualization which cannot be manufactured using conventional processes such as casting or forging. By proper control of the SLM processing parameters, characteristics of the alloy can be optimized. In the present work, 316L stainless steel (SS), as a widely used biomedical material, is investigated in terms of the effects of scanning speed on in vitro biocompatibility during SLM process. Cytotoxicity assay is adopted to assess the in vitro biocompatibility. The results show the scanning speed strongly affects the in vitro biocompatibility of 316L SS parts and with prolongs of incubation time, the cytotoxicity increase and the in vitro biocompatibility gets worse. The optimal parameters are determined as follows: scanning speed of $900 \mathrm{~mm} / \mathrm{s}$, laser power of $195 \mathrm{~W}$, hatch spacing of $0.09 \mathrm{~mm}$ and layer thickness of $0.02 \mathrm{~mm}$. The processing parameters lead to the change of surface morphology and microstructures of samples, which can affect the amount of toxic ions release, such as $\mathrm{Cr}$, Mo and $\mathrm{Co}$, that can increase risks to patient health and reduce the biocompatibility.
\end{abstract}

\section{Introduction}

With an increased demand for fast and less expensive product development, rapidly manufacturing parts from metal powders without moulds becomes more and more desirable [1,2]. Additive manufacturing (AM) has received great attention over the past decade [3],[4],[5].AM by selective laser melting (SLM) is an advanced manufacturing process which uses lasers to melt metal powders one layer at a time to produce components from 3D CAD models, as shown in Fig. 1. The process is suitable to manufacture complex parts which cannot be manufactured using conventional processes such as casting or forging. The process of selective laser melting is a potential manufacturing route for biomedical parts, aero applications, and dental prostheses [6]. Compared with other biomedical metallic materials, 316L stainless steel (SS) has been widely used for biomedical material to make artificial joints, bone plate and bone screw and other medical devices due to its outstanding mechanical properties, corrosion resistance and low price $[7,8]$. The process has been successfully demonstrated [6] to manufacture $316 \mathrm{~L} \mathrm{SS}$ parts. Some investigation about the mechanical properties and corrosion resistance of $316 \mathrm{~L}$ SS parts has been reported $[9,10]$. However, the release of potential toxic ions such as $\mathrm{Cr}$, Ni and Mo, in $316 \mathrm{~L}$ parts manufactured via the SLM route, prevents its use for applications in dental prostheses, which also increases risks to patient health. Therefore, during the SLM process, the researchers can determine the input parameters to get the desired product quality in time to meet the needs [11]. The properties of SLM shaped parts are influenced by the process parameters, such as the scanning speed, the laser power and the scanning distance $[12,13]$. The influence of processing parameters on the microstructure and mechanical properties of the final parts for different materials has been studied [14-20]. The parameters of SLM stainless steel have been optimized and evaluated in some studies. Riemer etal. [21] have been studied the fatigue crack growth behavior of SLM 316L stainless steel. The feasibility of the preparation of cellular lattice structure of SLM stainless steel has been studied by Yan et al. [22]. Li etal. [23] have studied the optimization of four process parameters: laser power, scanning speed, scanning spacing and layer thickness, to obtain compact specimens. Laser melting and numerical simulation of 316L powder have been used to evaluate the influence of laser power, scanning speed and beam size on the melting zone and the phenomenon of the ball performed by Antony etal. [24]. Hence, effects of scanning speed on in vitro biocompatibility of $316 \mathrm{~L}$ SS parts manufactured via SLM are experimentally investigated in this study. 


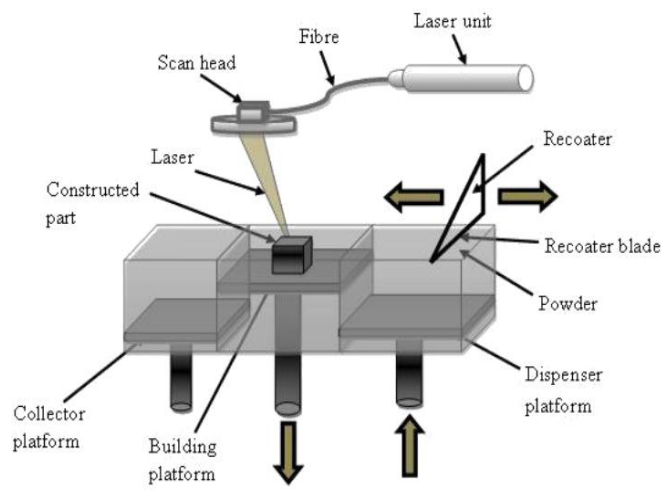

Figure 1. Schematic diagram of SLM process

\section{Materials and methods}

The material used in our experiments is $316 \mathrm{~L}$ stainless steel powder (size range from $24 \mu \mathrm{m}$ to $59 \mu \mathrm{m}$, the mean particle size $38 \mu \mathrm{m}$ ), manufactured via gas atomization, as shown in Fig. 2 and Fig. 3. The specification and actual composition of the alloy are shown in Table 1. Based on the information provided by the supplier, this powder is recommended in medical field and has a reported a tensile strength of 590-690 MPa in horizontal direction and $485-595 \mathrm{MPa}$ in vertical direction, a yield strength of 470-590 $\mathrm{MPa}$ in horizontal direction and 380-560 $\mathrm{MPa}$ in vertical direction, Young's modulus of typical 185 $\mathrm{GPa}$ in horizontal direction and $180 \mathrm{GPa}$ in vertical direction, elongation at break of typical $25-55 \%$ in horizontal direction and 30-70\% in vertical direction, and hardness of typical $85 \mathrm{HRB}$ when standard SLM building parameters and strategies are used.In order to avoid the test errors, 15 cylindrically-shaped samples (10 $\mathrm{mm}$ diameter and $10 \mathrm{~mm}$ thickness, as shown in Fig. 4) are manufactured by EOS M280 (Fig. 5) and divided into five groups. The processing parameters are: scanning speed (v) of $800 \mathrm{~mm} / \mathrm{s}, 900 \mathrm{~mm} / \mathrm{s}, 1050 \mathrm{~mm} / \mathrm{s}, 1100$ $\mathrm{mm} / \mathrm{s}, 1200 \mathrm{~mm} / \mathrm{s}$, laser power $(\mathrm{P})$ of $195 \mathrm{~W}$, hatch spacing (h) of $0.09 \mathrm{~mm}$ and layer thickness (d) of 0.02 $\mathrm{mm}$. All samples are cleaned in ultrasonic bath with acetone (15 $\mathrm{min})$, ethanol (15 $\mathrm{min}$ ) and distilled water (3 min) and then dried in open air. All samples are sterilized in autoclave for $20 \mathrm{~min}$. Five group samples are immersed in $15 \mathrm{ml}$ centrifuge tube at a ratio of $3: 1$ volume of DMEM supplemented with $10 \%$ fetal calf serum to surface area of the specimens for $72 \mathrm{~h}$ at $37{ }^{\circ} \mathrm{C}$ environment. After $72 \mathrm{~h}$, the samples are token out from the DMEM.

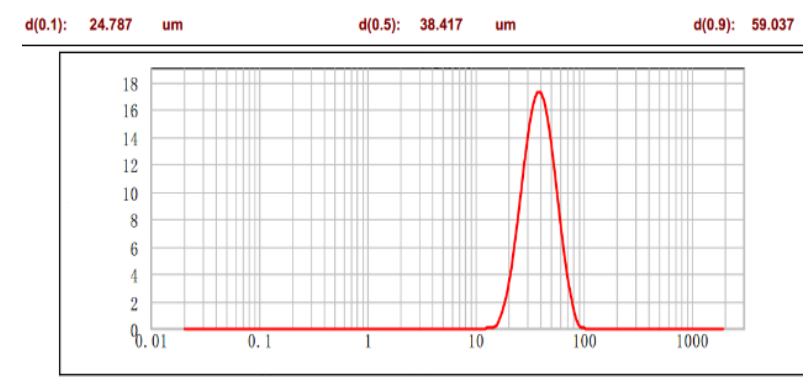

Figure 2. SEM of 316L powder

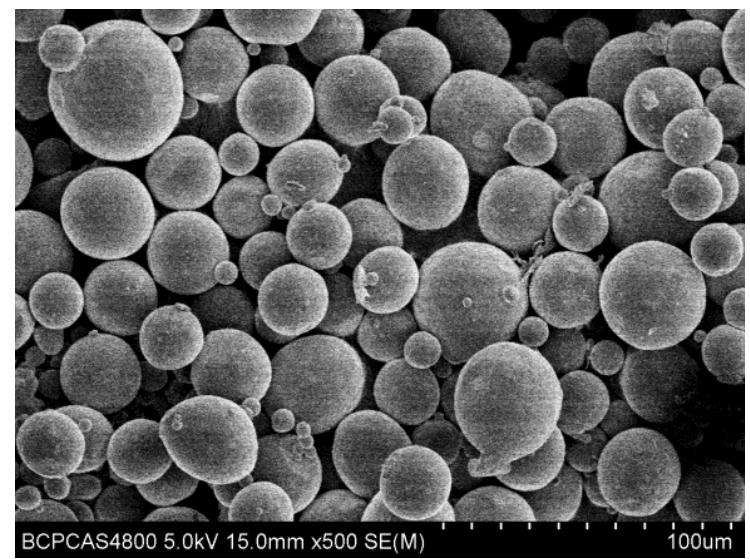

Figure 3. SEM of 316L powder

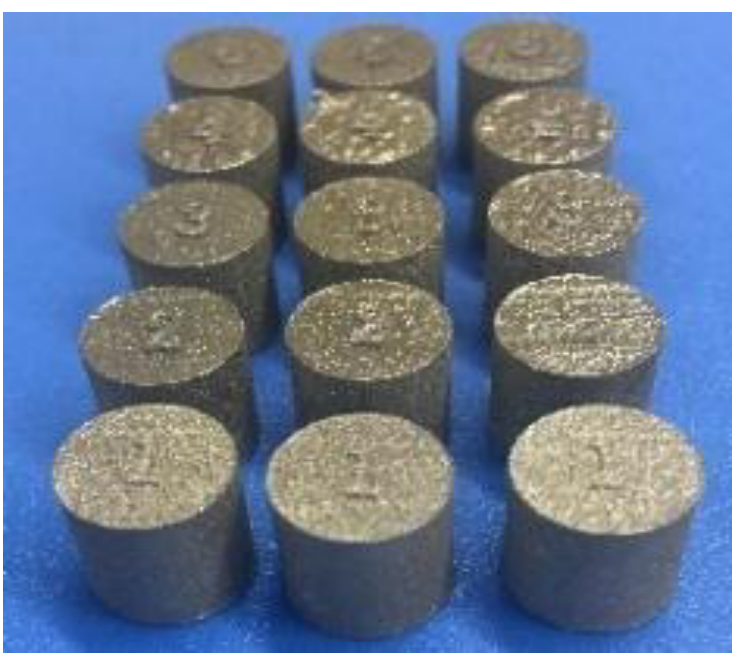

Figure 4. Cylindrically-shaped samples

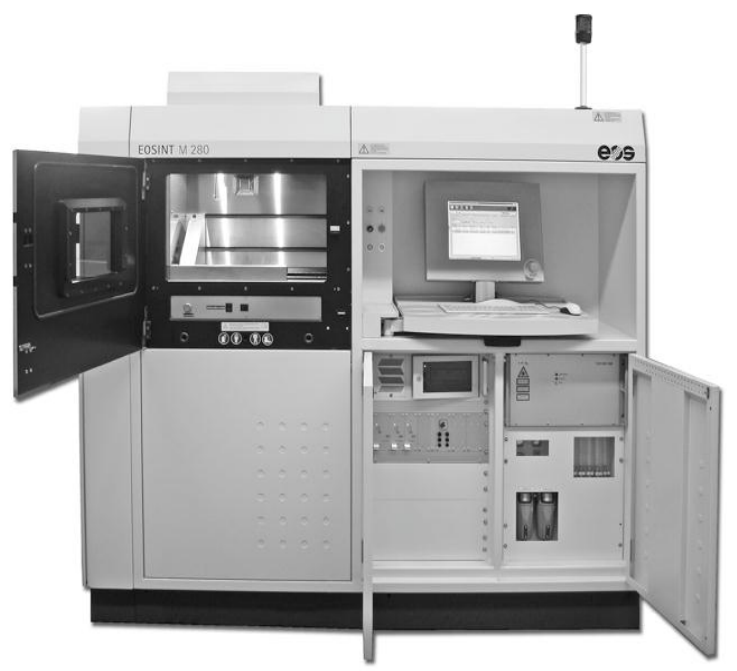

Figure 5.EOS M280

Table 1. Composition of $316 \mathrm{~L}$ stainless steel powder.

\begin{tabular}{|c|c|c|c|c|c|c|c|c|c|}
\hline Grade $316 \mathrm{~L}$ & $\mathrm{C}$ & $\mathrm{Cr}$ & $\mathrm{Ni}$ & $\mathrm{Mo}$ & $\mathrm{Mn}$ & $\mathrm{Si}$ & $\mathrm{P}$ & $\mathrm{S}$ & $\mathrm{Fe}$ \\
\hline $\mathrm{Wt} \%$ & 0.030 & 16.97 & 13.11 & 2.35 & 2.00 & 0.75 & 0.025 & 0.010 & Balance \\
\hline
\end{tabular}

In our study, cytotoxicity assay is adopted to assess the in vitro biocompatibility of $316 \mathrm{~L}$ SS parts. Cytotoxicity assay is performed by using a CCK- 8 assay 
to evaluate the HEK 293T cells. HEK 293T cells are digested with trypsin and seeded at 2000 cells/well into a 96-well culture plate containing the DMEM medium, and cultivated in a $5 \% \mathrm{CO}_{2}$ humidified environment at $37{ }^{\circ} \mathrm{C}$ for $24 \mathrm{~h}$, then the original culture solution is removed when cells are growth attached to the wall. Each well is washed with phosphate buffer solution (PBS), and then the solution of the five group samples are added, and two groups are provided with DMEM culture medium as the control groups. The cell inhibition rate (CIR) is examined using CCK-8 after $24 \mathrm{~h}$ and $72 \mathrm{~h}$ of cell culture, which shows a positive correlation with the cytotoxicity of $316 \mathrm{~L}$ SS parts. Microplate reader is used to test the optical density (OD) of each solution. The CIR is calculated by the following equation:

$$
C I R=\left(1-\frac{E_{O D}}{C_{O D}}\right) \times 100 \%
$$

where $\mathrm{E}_{\mathrm{OD}}$ indicates the $\mathrm{OD}$ of experimental groups, $\mathrm{C}_{\mathrm{OD}}$ indicates the OD of control groups.

\section{Results and conclusions}

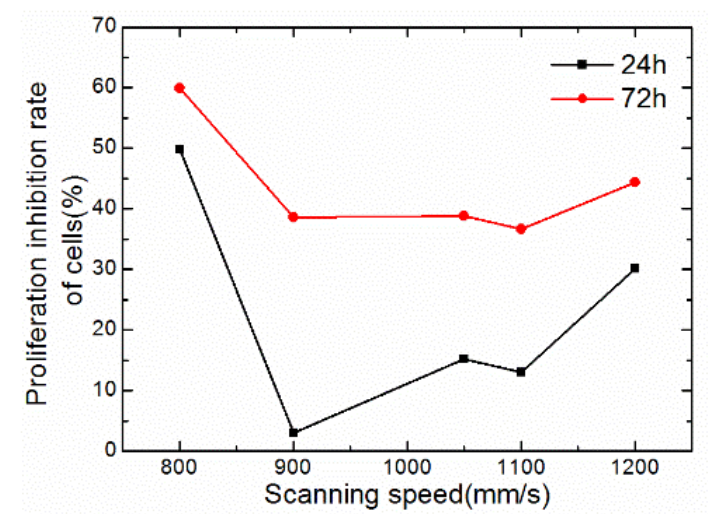

Figure 6. Inhibition rate of HEK $293 \mathrm{~T}$ cells after $24 \mathrm{~h}$ and $72 \mathrm{~h}$

Fig.6 shows the CIR after $24 \mathrm{~h}$ and $72 \mathrm{~h}$. After $24 \mathrm{~h}$, the highest cytotoxicity in the solution (scanning speed of $800 \mathrm{~mm} / \mathrm{s}$ ) is obtained, the CIR is $49.82 \%$. For the scanning speed of $900 \mathrm{~mm} / \mathrm{s}$, the CIR of the solution is $3.05 \%$, which is the lowest cytotoxicity of five groups. As the scanning speed increases, the cytotoxicity in corresponding solutions are various, and $15.21 \%, 13.04 \%$, and $30.11 \%$ of the CIR are for the cases of $1050 \mathrm{~mm} / \mathrm{s}$, $1100 \mathrm{~mm} / \mathrm{s}$ and $1200 \mathrm{~mm} / \mathrm{s}$, respectively. The experimental data shows that the scanning speed strongly affects the cytotoxicity of the 316L SS parts. The inhibition rate of HEK $293 \mathrm{~T}$ cells in different solutions after $72 \mathrm{~h}$ is also investigated. The CIR in solutions are $59.92 \%, 38.53 \%, 38.86 \%, 36.60 \%$ and $44.38 \%$ for the cases of $800 \mathrm{~mm} / \mathrm{s}, 900 \mathrm{~mm} / \mathrm{s}, 1050 \mathrm{~mm} / \mathrm{s}, 1100 \mathrm{~mm} / \mathrm{s}$ and $1200 \mathrm{~mm} / \mathrm{s}$. The experiments shows that: 1) after $24 \mathrm{~h}$, the lowest cytotoxicity is obtained (scanning speed of 900 $\mathrm{mm} / \mathrm{s}$ ), while the highest value is CIR $49.82 \%$ (scanning speed of $800 \mathrm{~mm} / \mathrm{s}$ ); and 2) after $72 \mathrm{~h}$, the lowest and highest value of cytotoxicity is CIR $36.60 \%(1100 \mathrm{~mm} / \mathrm{s})$ and $59.92 \%(800 \mathrm{~mm} / \mathrm{s})$. It is found that: 1$)$ with prolongs of incubation time, the cytotoxicity increase. And the in vitro biocompatibility of $316 \mathrm{~L} \mathrm{SS}$ parts manufactured via SLM gets worse. 2) processing parameters: scanning speed of $800 \mathrm{~mm} / \mathrm{s}$, laser power of $195 \mathrm{~W}$, hatch spacing of $0.09 \mathrm{~mm}$ and layer thickness of $0.02 \mathrm{~mm}$, is not suitable for the manufacture of biomedical parts.

As shown in Fig. 6, the scanning speed has strong effects on the in vitro biocompatibility of $316 \mathrm{~L} \mathrm{SS}$. The main reasons for the use of $316 \mathrm{~L}$ SS are its low cost, good machining performance and mechanical properties. The increasing use of this metallic alloy in the medical field has led to an enormous amount of studies related to health. However, clinical experience has revealed that metal ions, which are released from dental restorations, can provoke systemic and local allergic reactions. In addition, these metal ions may also have an adverse effect on adjacent oral soft tissues and nearby alveolar bone. The severe and prolonged processes can lead to failure of the implant. Nickel、Chromium、Molybdenum have been found to be the main elements resulting from dissolution of 316L SS alloys. Yamamoto et al. [25] have been established the sequence from the highest toxic element to the lowest toxic element as being: $\mathrm{Ni}>\mathrm{Cr}>\mathrm{Mo}$ for $\mathrm{L} 929$ cells. Particularly, $\mathrm{Ni}^{3+}$ undergoes mitochondrial redox metabolism and leads to intermediate reactive oxygen radical formation, which is toxic for the cell. Contrary to a relatively low nickel ion concentration, a higher concentration lead to in vitro cell death and the integrity of a fibroblast monolayer loss, which affect cellular metabolism. In fact, this element can cause allergic sensitization especially in females according to a report that indicate $30 \%$ of women had skin allergy to objects containing nickel. The presented in vitro biocompatibility data shows that the scanning speed has strong effects on the in vitro cytotoxicity whereas has no significant effects on the hemolysis. Extensive in vitro studies [26-28] have suggested that metallic dental restorations release metal cations due to corrosion and $316 \mathrm{~L} \mathrm{SS}$ is always accompanied by corrosion problems. It is reported that microstructure might, in fact, significantly influenced corrosion, that is to say, significantly influenced biocompatibility [29]. Material degradation of stainless steels begins whenever they experience temperature in the range $450-800{ }^{\circ} \mathrm{C}$. After sufficient time at temperature, intermetallic compounds (principally $\mathrm{Cr}$ carbides) precipitate in grain boundaries and (later) inside the grains as well. This precipitation creates a condition known as sensitization that ruins corrosion resistance [30]. However, the detailed mechanism is still under investigation. The further study will focus on detection of toxic ion (including ion type and amount of release) and the effects of processing parameters (including power, scanning speed, and scanning strategy) on surface morphology, such as porosity, density and dislocation.

\section{References}

1 T.H.C. Childs, C. Hauser, M. Badrossamay, P.I. Mech, Eng. B: J. Eng. 219, 339-357, (2005).

2 K. Osakada, M. Shiomi, Int. J. Mach. Tools Manuf. 46 1188-1193, (2006). 
3 G.N. Levy, R. Schindel, J.-P. Kruth, Rapid manufacturing and rapid tooling with layer manufacturing (LM) technologies, state of the art and future perspectives, CIRP Annals, 52/2: 583- 609, (2003).

4 Hopkinson, N., Dickens, P., rapid prototyping for direct manufacture, Rapid Prototyping J., 7/4: 197 202 (2001).

5 J.-P. Kruth, G. Levy, F. Klocke, T.H.C. Childs, Consolidation phenomena in laser and powder-bed based layered manufacturing, CIRP Annals, 56/2: 730-759, (2007).

6 J.A. Cherry, H. M. Davies, S. Mehmood, N.P. Lavery, S. G.R. Brown, J. Sienz. Int. J Adv. Manuf. Techno.176, 869-879, (2015).

7 L. Zhou, K. Nakata, T. Tsumura. Journal of Materials Engineering and Performance 23, 37183726, (2014).

8 S.M. Hosseinalipour, A. Ershad-Langroudi, A.N. Hayati. Progress in Organic Coatings 67, 371-374, (2010).

9 B. Zhang, L. Dembinski, C. Coddet. Materials Science and Engineering A 584, 21-31, (2013).

10 Y. Sun, A. Moroz, K. Alrbaey. Journal of materials engineering and performance 23, 518-526, (2014).

11 V.S. Thangarasu, R .Sivasubramanian, HIGH SPEED CNC MACHINING OF AISI 304 STAINLESS STEEL; OPTIMIZATION OF PROCESS PARAMETERS. International Journal of Mechanical Engineering and Robotics Research, 1(9), (2012).

12 G. Casalino, S.L. Campanelli, N. Contuzzi et al. Experimental investigation and statistical optimisation of the selective laser melting process of a maraging steel. Optics \& Laser Technology, 65: 151-158, (2015).

13 A. Simchi, Direct laser sintering of metal powders: Mechanism, kinetics and microstructural features. Materials Science and Engineering: A, 428(1): 148158, (2006).

14 D. Gu, Y. Shen, Balling phenomena in direct laser sintering of stainless steel powder: metallurgical mechanisms and control methods. Materials \& Design, 30(8): 2903-2910, (2009).

15 A. Simchi, F. Petzoldt, H. Pohl, On the development of direct metal laser sintering for rapid tooling. Journal of Materials Processing Technology, 141(3): 319-328, (2003).

16 E.O. Olakanmi, Selective laser sintering/melting (SLS/SLM) of pure $\mathrm{Al}, \mathrm{Al}-\mathrm{Mg}$, and Al-Si powders: Effect of processing conditions and powder properties. Journal of Materials Processing Technology, 213(8): 1387-1405, (2013).

17 E. Sallica-Leva, A.L. Jardini, J.B. Fogagnolo, Microstructure and mechanical behavior of porous Ti-6Al-4V parts obtained by selective laser melting. Journal of the mechanical behavior of biomedical materials, 26: 98-108, (2013).
18 J.P. Kruth, L. Froyen, J. Van Vaerenbergh, et al. Selective laser melting of iron-based powder. Journal of Materials Processing Technology, 149(1): 616622, (2004).

19 E. Chlebus, B. Kuźnicka, T. Kurzynowski et al. Microstructure and mechanical behaviour of $\mathrm{Ti}-6 \mathrm{Al}-7 \mathrm{Nb}$ alloy produced by selective laser melting. Materials Characterization, 62(5): 488-495, (2011).

20 R. Wauthle, B. Vrancken, B. Beynaerts et al. Effects of build orientation and heat treatment on the microstructure and mechanical properties of selective laser melted Ti6Al4V lattice structures. Additive Manufacturing, 5: 77-84, (2015).

21 A. Riemer, S. Leuders, M. Thöne et al. On the fatigue crack growth behavior in $316 \mathrm{~L}$ stainless steel manufactured by selective laser melting. Engineering Fracture Mechanics, 120: 15-25, (2014).

22 C. Yan, L. Hao, A. Hussein et al. Advanced lightweight $316 \mathrm{~L}$ stainless steel cellular lattice structures fabricated via selective laser melting. Materials \& Design, 55: 533-541, (2014).

23 R. Li, Y. Shi, Z. Wang et al. Densification behavior of gas and water atomized $316 \mathrm{~L}$ stainless steel powder during selective laser melting. Applied Surface Science, 256(13): 4350-4356, (2010).

24 K. Antony, N. Arivazhagan, K. Senthilkumaran. Numerical and experimental investigations on laser melting of stainless steel $316 \mathrm{~L}$ metal powders. Journal of Manufacturing Processes, 16(3): 345-355, (2014).

25 A. Yamamoto, R. Honma, M. Sumita. Cytotoxicity evaluation of 43 metal salts using murine fibroblasts and osteoblastic cells. Journal of biomedical materials research, 39(2): 331-340, (1998).

26 Y.C. Tang, S. Katsuma, S. Fujimoto et al. Electrochemical study of Type 304 and $316 \mathrm{~L}$ stainless steels in simulated body fluids and cell cultures. Acta Biomaterialia, 2(6): 709-715, (2006).

27 R. Nishimura, A. Sulaiman, Y. Maeda. Stress corrosion cracking susceptibility of sensitized type 316 stainless steel in sulphuric acid solution. Corrosion Science, 45(2): 465-484, (2003).

28 R.A. Antunes, A.C.D. Rodas, N.B. Lima et al. Study of the corrosion resistance and in vitro biocompatibility of PVD TiCN-coated AISI 316L austenitic stainless steel for orthopedic applications. Surface and Coatings Technology, 205(7): 20742081, (2010).

29 X.Z. Xin, N. Xiang, J. Chen et al. In vitro biocompatibility of $\mathrm{Co}-\mathrm{Cr}$ alloy fabricated by selective laser melting or traditional casting techniques . Materials Letters, 88: 101-103, (2012).

30 D.H. Kumar, A.S. Reddy. STUDY OF MECHANICAL BEHAVIOR IN AUSTENITIC STAINLESS STEEL 316 LN WELDED JOINTS. Int. J. Mech. Eng. Rob. Res, 2: 37-56, (2013). 